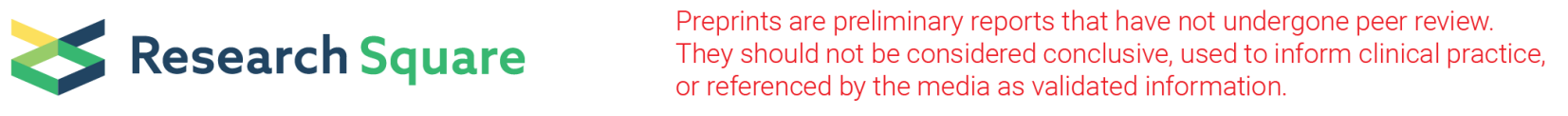

\title{
Spatio-temporal Bamboo Forest Dynamics in the Lower Beles River Basin, North-western Ethiopia
}

Shiferaw Abebe ( $\sim$ shiferaw1a@gmail.com)

Bahir Dar University https://orcid.org/0000-0002-5660-6461

Amare Sewnet Minale

Bahir Dar University

Demel Teketay

Botswana University of Agriculture and Natural Resources

Research

Keywords: Drivers, Ethiopia, Lower Beles River Basin, O. abyssinica, Remote sensing

Posted Date: December 1st, 2020

DOl: https://doi.org/10.21203/rs.3.rs-113842/v1

License: () (i) This work is licensed under a Creative Commons Attribution 4.0 International License. Read Full License 


\section{Abstract}

Introduction: Bamboo forests, which are an integral part of the eco-system and an important source of socio-economic life for rural communities in the vast savannah lowlands of Ethiopia, are experiencing significant changes. Therefore, examining bamboo forest cover changes and identifying responsible drivers for the changes are of the greatest importance for sustainable management of these useful resources. This study was intended to examine the spatiotemporal bamboo forest dynamics in the Lower Beles River Basin, north-western Ethiopia.

Method: A combination of pixel-based hybrid classification techniques and Normalized Difference Vegetation Index (NDVI) was employed to analyze bamboo forest cover changes from 1985 - 2019. Focus group discussions, questionnaire, key informant interview and observation were used to identify the drivers for bamboo forest cover change.

Results: The study findings indicate that bamboo has experienced significant spatio-temporal change over the study period (1985 - 2019 ) in the study District. In the base year (1985), bamboo covered 5.1\% (5,277.1 ha) of the study area. Significant decline in bamboo forest had occurred in 2001 when the bamboo forests suffered the greatest devastation and shirked to $1.6 \%$. In 2019 , the bamboo has been rehabilitated from degradation and increased significantly. However, the net change over the study periods was negative where the bamboo forests declined by $0.8 \%$ (831.14 ha).

Conclusion: In conclusion, the observed changes in bamboo forest cover was driven by an interplay of multiple factors. Agricultural land expansion, wildfire, free grazing, lack of regulatory mechanisms and improper harvesting and expansion of settlement areas were the top five drivers respectively while conflict, mass flowering and tenure contributed for the change. Therefore, the bamboo forests deserve great attention, and the results from this study imply the need for the concerted efforts of stakeholders for sustainable management, utilization and conservation of the bamboo resources.

\section{Introduction}

Bamboos are crucial vegetation resources mostly distributed in tropical and sub-tropical areas of Asia, Africa and Latin America (Ben-zhi et al. 2005; Zhang et al. 2014; Zhuang et al. 2015), covering 33 million ha area and accounting for about 1.0\% of the forest area in the world (Zhou et al. 2011; Du et al. 2018). They are unique in their capacity to meet a wide range of socio-economic, sustainability, and conservation focused objectives (Sohel et al. 2015; Ling et al. 2016; Li et al. 2020), owing to their rapid growth, ease of propagation, and the range of ecosystem services they provide (Zhou et al. 2011; Nath et al. 2015; Li et al. 2016). Bamboos have very crucial ecological and environmental functions in soil and water conservation, land rehabilitation, and carbon sequestration due to their biological characteristics (Ben-zhi et al.s 2005; Yiping et al. 2010; Akinlabi et al. 2017). Therefore, mapping the spatio-temporal bamboo forest change is critical to devise strategies for sustainable use of bamboo resources (Li et al. 2020).

In Africa, Ethiopia stands in the first position for its bamboo forest resources. The country possesses about 67 and $7 \%$ of the total bamboo forest areas in Africa and the world, respectively (Endalamaw et al. 2013; Mekonnen et al. 2014; TsinghuaUniversity and INBAR 2018). It has two indigenous species of bamboo, namely Yushania alpina (K. Schum.) W.C. Lin (highland bamboo) and Oxytenanthera abyssinica (A. Rich) Munro (lowland bamboo) with area coverage of more than one million ha (Embaye 2000; Desalegn and Tadesse 2015; Zhao et al. 2018). The focus of the present study is on 0 . abyssinica, which grows in the vast western savannah lowlands along major river valleys bordering Sudan (Kelbessa et al. 2000), and constitutes about $85 \%$ of the total bamboo forest in the country (Sertse et al. 2011; Endalamaw et al. 2013; Desalegn and Tadesse 2015; Boissière et al. 2019).

However, reliable and consistent data on bamboo resources are limited. Different inventories conducted so far has been reporting different figures about bamboo resources. In 1960s, the total area of bamboo was estimated at 1.5 million ha (Lobovikov et al. 2007). However, a study conducted by GIZ-LUSO Consult Gmbh (1997) reported that there is $700,000-850,000$ ha of lowland bamboo and 129,626 ha of highland bamboo in Ethiopia. The International Bamboo and Rattan Network, currently, Organization (INBAR), production to consumption study (Kelbessa et al. 2000), reported the availability of 1.1 million ha of bamboo: 950,000 ha of lowland bamboo and 150,000 highland bamboo. Lobovikov et al. (2007) estimated that the bamboo forest area was about 849,000 ha in 2005. A recent remote sensing-based study conducted by Zhao et al. (2018) reported that Ethiopia possess 1.47 million ha of bamboo resources.

From the above reports, it is possible to infer that the bamboos have been undergone with spatial and temporal changes. Over the years, the bamboo forests have been under high pressure and suffering great depletion. The expansion of agricultural land and changing bamboo stands to other land uses, free grazing and fire hazards are important anthropogenic factors causing depletion of bamboos (Kindu and Mulatu 2009; INBAR 2010; Desalegn and Tadesse 2015; Boissière et al. 2019), when gregarious flowering is the major natural cause contributing for their degradation (Sertse et al. 2011). Nevertheless, little efforts were made so far to counterbalance the problem and reliable and consistent data on the status of the bamboo resource base as well as the policy options for sustainable bamboo resource use and development are scanty (Tsinghua University and INBAR 2018; Boissière et al. 2019; EFCC 2020).

The use of remote sensing data has been instrumental in monitoring the changing pattern of vegetation across diverse landscapes. Hence, several studies have been conducted to identify and map bamboo forest cover using remotely sensed data at global scale (Wang et al. 2009; Goswami et al. 2010; Xu et al. 2012; Carvalho et al. 2013; Han et al. 2014; Li et al. 2016; Fava and Colombo 2017; Du et al. 2018; Liu et al. 2018; Zhao et al. 2018; Zhang et al. 2019) However, studies conducted at the local level are of critical importance to better understand the cumulative impact at multiple scales (Sohl et al. 2004; Shah and Sharma 2015).

Hitherto, very little scientific studies have been conducted on spatio-temporal cover change of bamboo forests (Bessie et al. 2016; Zhao et al. 2018). Lack of reliable and consistent data on bamboo resources has impeded the proper management bamboo forests deserve and limited their potential in providing ecological and socio-economic services (Nat h et al. 2015; Li et al. 2016, 2020; Liu et al. 2018). In the milieu of sever bamboo resource degradation, on one hand, and the availability of abundant resource base, on the other hand, some authors deem that more research is critical in the lowlands of north-western 
Ethiopia, where the country's largest bamboo resource base is found. The rationale behind such scientific studies is that empirical evidence on spatio-temporal bamboo forest cover change is a decisive instrument to devise strategies for sustainable bamboo resource management. Therefore, the objectives of this study were: (i) to examine the spatial and temporal changes of the $O$. abyssinica forest cover between 1985 - 2019, and (ii) to identify drivers of the changes of $O$. abyssinica forest cover in the Lower Beles River Basin, north-western Ethiopia.

\section{Materials And Methods The study area}

The study area, Mandura District is one of the bamboo producing areas in Lower Beles River Basin, north-western Ethiopia. The District located between $10^{\circ}$ $50^{\prime} 55^{\prime \prime}$ to $11^{\circ} 10^{\prime} 10^{\prime \prime} \mathrm{N}$ and $36^{\circ} 02^{\prime} 48^{\prime \prime}$ to $36^{\circ} 32^{\prime} 42^{\prime \prime} \mathrm{E}$, with a total area of $1,045 \mathrm{~km}^{2}$. It is part of the north-western lowlands where elevation ranges from 800 to 2186 m (Fig. 1). The basement complex rock covers the vast areas where, few areas, particularly, the Kar Mountain escarpments, situated in the northeastern part of the District are covered with plateau basalts (Addisu 2010). Nitosols, cambisols, luvisols and leptosols are the dominant soils in the sub-basin (Yilma and Awulachew 2009).

In the District, there are both perennial and seasonal rivers and streams that flow towards Gilgel Beles River, which is main tributary of River Beles (Fig. 1). The District shows a unimodal rainfall distribution pattern and ranges approximately, from 1,052 to 1,957 mm whereas temperature ranges between a maximum of 35 to $40^{\circ} \mathrm{C}$ and a minimum of 18 to $20^{\circ} \mathrm{C}$ (Nyssen et al., 2018). Generally, climate of the District is classified as wet tropical (wet kolla) except small areas around the Kar Mountain, which is wet sub-topical (wet woynadega).

The Gumuz, Amhara, Agew and Shinasha are the major ethnic groups in the area while the Oromo represent a minority. About $81.5 \%$ of the population is rural dweller (CSA 2007). Mixed farming is the main economic activity of people in the study area. Most people are engaged in both traditional crop production and livestock rearing practices. Dominant crops are maize (Zea mays L.), sorghum [Sorghum bicolor (L.) Moench.], sesame (Sesamum indicum L.) and groundnut (Arachis hypogaea L.). Cattle and goats are the main livestock resources kept in the study area.

The major land use/covers are woodlands, grassland, shrub/ bushland, bamboo, agricultural land and barren land settlement (Emiru and Taye 2012). The natural vegetation is characterized by a variety of shrubs, bush with woody trees and elephant grass undergrowth and 0 . abyssinica forests (Addisu 2010; Bessie et al. 2016).

\section{Methods}

\section{Data sources}

The study used both spatial and non-spatial (socio-economic) datasets. These datasets were collected from various sources, which include: Landsat imageries, Google Earth images, household survey questionnaire, focus group discussion, key informant interview and filed observation. Other datasets were collected from government reports, published literature and policy documents.

\section{The remote sensing data and techniques}

Satellite imageries of Landsat 5 (TM), Landsat 7 (ETM+), and Landsat 8 (OLI_TIRS) were taken for the year 1985, 2001 and 2019 respectively (Table 1). All Landsat images were taken during leaf-off season (Wang et al. 2009; Zhao et al. 2018). The reasons behind for choosing of years and seasons were: (1) the availability of cloud free (below $10 \%$ cloud cover) and good quality satellite images; and (2) the dry season is a proper time to spectrally distinguish bamboo from leaf-shedding vegetation and co-occurring grasses and shrubs. In addition, the Advanced Space Borne Radiometer (ASTER) Global Digital Elevation Model (GDEM), ASTER GDEM, acquired from USGS Earth explorer (http://gdex. cr.usgs.gov/gdex), was used to determine the elevation of the study area.

\section{Image pre-processing}

In order to maximize classification accuracy, input images must have minimal contamination from clouds, haze, shadow, or other disturbances (Azzari and Lobell 2017). Thus, haze reduction and atmospheric correction was conducted on satellite imageries using Atmospheric and Topographic Correction (ATCOR) software which is an add-on module to ERDAS (Wang et al. 2009). Following the availability of panchromatic data, pan-sharpening or image fusion was applied to merge the high resolution panchromatic band of Landsat 7 (ETM+) and Landsat 8 (OLI_TIRS) with Multispectral (MS) images of 2001 and 2019 reference years (Chen et al. 2001; Rogan and Chen 2004; Sahle et al. 2016).

Clipping, geo-referencing, layer stacking and image enhancement were applied on Landsat imageries prior to image classification (Rogan and Chen 2004). In order to ensure consistency among data sets throughout the classification and analysis process, all imageries were projected to the Universal Transverse Mercator (UTM) Projection System, Zone 37N and Datum of World Geodetic System 84 (WGS84).

\section{Image classification}

According to Rogan and Chen (2004), the hybrid classification method improves accuracy than using supervised or unsupervised technique alone. Hence, the hybrid pixel-based image classification method, which combines both unsupervised and supervised classifications (Rogan and Chen 2004; Lillesand et al. 
2015) was employed. Primarily, the unsupervised classification was carried out in Iterative Self Organizing (ISO) data analysis algorithm (Lillesand and Kiefer 2007) to determine the number of land use/land cover classes (LULCC) in the study area.

However, mapping bamboo forests using the spectral approach alone is challenging due to the similarity of spectra between bamboo and other forest types (Wang et al. 2009; Zhang et al. 2019). To offset the problem, phenological information plays a crucial role in bamboo extraction (Zhao et al. 2018 ; Zhang et al. 2019). Similarly, it was noted that taking into account phenology when performing land cover classification yield more accurate maps (Knight et al. 2006; Simonetti et al. 2014; Fan et al. 2015). In this regard, remote sensing phenology studies use data gathered by satellite sensors that measure wavelengths of light absorbed and reflected by green plants, and transform raw satellite data of these light waves into vegetation indices (Simonetti and Simonetti 2014).

In remote sensing scene, there are several vegetation indices highlighting vegetation bearing area (Gandhi et al. 2015). The most widely used indices in research on global environmental change, is the Normalized Difference Vegetation Index (NDVI) (Bhandari et al. 2012). It is calculated from the visible red and near-infrared (NIR) light reflected by vegetation as follows (Simonetti et al. 2014):

$$
\text { NDVI }=\frac{\text { NIR }- \text { RED }}{\text { NIR }+ \text { RED }}
$$

Hence, leaf-off season Landsat 8 imageries spanning from 2015 - 2019 were used to compute the NDVI map of the study area. Each feature has its own spectral reflectance, varying according to the wavelength (Simonetti et al. 2014). Therefore, as our aim was to discriminate bamboo form other vegetation, we took 100 points ( 60 for classification and 40 for validation) from bamboo forest prior to classifying the NDVI images. Then, NDVI images were classified in to five land cover classes: non-vegetated land, grass, bamboo, shrub/ bushland and woodland (Fig. 2).

Values in NDVI range between -1 to 1. According to Bhandari et al. (2012), very low value of NDVI (0.1 and below) correspond to barren areas of rock, sand or snow. Moderate values ( 0.2 to 0.3$)$ represent shrub and grassland, while high value (0.6 to 0.8$)$ indicates temperate and tropical rainforests. Bare soil is represented with NDVI values, which are closer to 0 , and water bodies are represented with negative NDVI values. In our study, the average NDVI value of bamboo was found between 0.14 to 0.165 , which was less than shrubs, but greater than grasses. When the maximum value of NDVI was low ( $0.4-0.58)$, the NDVI of bamboo was $0.14-0.162$. Whereas, as the value of NDVI reach as high as 0.6 and above, the bamboo had a value of $0.148-0.165$. Given this threshold value, the NDVI maps were produced for the year 1985, 2001 and 2019 (Fig 2). Finally, the NDVI maps of each year was used to extract features to aid and improve the supervised classification.

The supervised image classification, with maximum likelihood classification algorithm (Rogan and Chen 2004), was conducted using training samples collected from different sources. The highest number of samples were taken from bamboo land cover class in order to increase the classification accuracy. For 1985 and 2001 imageries, classification was undertaken with the help of high resolution Google Earth images, knowledge of elders, NDVI maps and color visualization and interpretation of the raw images (Lossou et al. 2019). For classifying 2019 Landsat imagery, field survey, NDVI maps and Google Earth datasets were used to collect training samples (Fig 3).

\section{Accuracy assessment}

Before proceeding to other activities, it was essential to evaluate the accuracy of the classification results (Liu and Mason 2016). Hence, accuracy assessment was conducted with independent samples collected through field survey, knowledge of elders and ancillary data, namely Google Earth images and NDVI maps, using stratified random sampling approach (FAO 2016). Then, confusion matrix or error matrix, which is one of most common means of expressing or assessing classification accuracy (Kindu et al. 2015; Liu and Mason 2016), was used for accuracy assessment purpose.

An error matrix compares information from reference data to information on the classified map for a number of sample area (Congalton 1991). The overall, producer's and user's accuracies were computed from error matrix. In addition, the omission and commission errors of bamboo and non-bamboo classes were calculated to evaluate the performance of the bamboo classification. Commission error is the percentage of pixels, classified as a certain class, which do not belong to that class according to the reference data. Omission error is the percentage of sample points, belonging to a certain class in the reference data, which were classified as other classes (Congalton 1991; Li et al. 2016). In addition, the kappa coefficient (K), the most commonly used statistical measure of classification accuracy and quality (Lillesand et al. 2015), was employed. The result of performing a kappa analysis is a KHAT statistic (an estimate of Kappa), which is agreement of accuracy (Congalton 1991).

The KHAT statistic (kappa coefficient) calculated as follows:

$$
K_{\text {hat }}=\frac{N \sum_{i=1}^{r} X_{i i}-\sum_{i=1}^{r}\left(X_{i+*} X_{+i}\right)}{N^{2}-\sum_{i=1}^{r}\left(x_{i+*}+X_{+i}\right)}
$$

where, $K_{\text {hat }}=$ kappa coefficient, $\mathrm{N}=$ total number of values, $N \sum_{i=1}^{r} X_{\text {ii }}=$ observed accuracy

and $\sum_{i=1}^{r}\left(X_{i+} * X_{+i}\right)=$ change accuracy.

\section{Change analysis}

Change analysis was carried out using post- classification image comparison technique. First, images of each reference years (1985, 2001 and 2019$)$ were classified separately. Then, change detection tasks were conducted. In order to examine the bamboo forest cover change over the study periods, we carried out 
change analysis on two intervals: 1985 - 2001 (first) and $2001-2019$ (second). The percentage of land cover change detection was conducted using the following formula (Kindu et al. 2013):

$$
\text { Land cover change }(\%)=\left(\frac{\text { Area }_{\text {final year- }} \text { Area }_{\text {initial year }}}{\text { Area }_{\text {initial year }}}\right) \times 100
$$

ArcGIS ${ }^{\circledR} 10.5$ and Earth Resource Data Analysis System (ERDAS) Imagine ${ }^{\circledR} 2014$ were used throughout the image pre-processing, processing, classification, post-classification as well as production of the final land cover maps of the study period.

\section{Socio-economic data and methods}

A total of 160 respondents were selected for questionnaire using systematic (random) sampling from resident lists found in the sample kebeles (the smallest administrative unit in Ethiopia), and the household head ( $\mathrm{HH}$ ) was interviewed (Creswell 2009). Prior to selecting sample respondents, sample villages or kebeles were selected based on information collected through reconnaissance survey, literature review and expert opinion. Accordingly, four kebeles: Kutirhulet, Deha-anzabuguna, Bahus and Deha-nubeshe were selected based of their bamboo forest coverage, representativeness and accessibility to transportation service.

Close-ended questions were prepared and written in English first and, later, translated to the Amharic Language. Amharic and Gumzigna (mother tongue language of the Gumuz community) languages were used (as required) to conduct the household surveys, while the data were recorded in Amharic and, then, translated into English. Four language translators were used to translate the Gumzigna language to Amharic and vice-versa. The main theme of the survey was to understand the perception of respondents about bamboo forest cover change and responsible drivers for the change.

Focus group discussions (FGDs) were held with 32 individuals selected from bamboo cultivators, kebele administrators and village level experts of the sample kebeles. The members discussed on issues regarding their views and experience on bamboo forest cover change and responsible drives for the change. During the entire discussion process, the investigator served as a facilitator while insiders fully participated in the dialogue (Lune and Berg 2017 ). Moreover, 12 elders, whose age was above 60 years old, and lived for long period (more than 35 years) in the study area, were selected as key informants. They were selected based on recommendations of village-level experts and officials.

\section{Data analysis}

Both qualitative and quantitative methods of data analyses were employed in the study (Creswell 2009). Qualitative technique of content analysis (Lune and Berg 2017) was used to analyze data generated through key informant interview, field observation and FGDs. In this method, the data were categorized in different themes and coded, organized categorically and chronologically, reviewed repeatedly and continually coded. Then, a list of major ideas was chronicled and transcribed to verbatim. Moreover, descriptive statistics of percentages and averages were used for describing sample respondents' responses and to summarize results generated through GIS and remote sensing techniques.

\section{Results}

\section{Accuracy assessment results}

According to accuracy assessment result (Table 3), user's and producer's accuracies for all classes ranged from 81.9 to $92.3 \%, 84.1$ to $95.4 \%$ and 87.1 to 95.2\% for 1985, 2001 and 2019 classifications, respectively. The overall accuracies were $85.5 \%$ (1985), 87.9\% (2001) and 89.1\% (2019). The producer's accuracies of bamboo were $82.9 \%$ (1985), 86.6\% (2001) and 88.1\% (2019), while the user's accuracies accounted for $81.9,85.5$ and $87.3 \%$ for 1985,2001 and 2019 maps, respectively.

Commission errors of bamboo were 17.1, 12.2 and 12.9\%, where omission errors were 15, 11.1 and $11.9 \%$ for reference year 1985,2001 and 2019 , respectively. For non-bamboo vegetation, omission errors were 19.7, 15.2 and $13.5 \%$ for grassland, $17.3,14.3$ and $15.1 \%$ for shrub/bushland and $7.7,9.1$ and 5\% for woodland in 1985, 2001 and 2019 classifications, respectively. Commission errors for grassland were 17.4\% (1985), 14.5\% (2001) and 12.3\% (2019); $13.9 \%$ (1985), 11.8\% (2001) and 12.7\% (2019) for shrub/bushland; and woodland had values of 13\% (1985), 10.4\% (2001), and 7.4\% (2019). These results indicate that bamboos are confused with non-bamboo vegetation, mainly, with grasses and shrubs though it declined in 2001 and 2019.

More specifically, as shown on the confusion matrix report (Table 4), $17.1 \%$ of reference points corresponding to bamboo were misclassified as grassland (11\%) and shrub/ bushland (6.1\%) in the 1985 map. Correspondingly, bamboo had the lowest producer's and user's accuracy values accounted for $82.9 \%$ and $81.9 \%$ respectively. This is due to the fact that major data used in this study was the medium resolution ( $30 \mathrm{~m})$ Landsat images, which is too coarse for mapping bamboo forest areas as they are often and confused and scattered with other forests (Zhao et al. 2018; Huy and Long 2019). Therefore, to offset this problem, image fusion was applied to merge the high resolution $(15 \mathrm{~m})$ panchromatic band of Landsat 7 (ETM+) and Landsat 8 (OLI_TIRS) with Multispectral (MS) images of 2001 and 2019.

Consequently, producer's and user's accuracies of bamboo increased when commission and omission errors declined in 2001 and 2019 maps (Table 3 ). The user's and producers' accuracies were 85.5 and $86.6 \%$ in 2001 , and 87.1 and $88.1 \%$ for 2019 maps, respectively. The EC of bamboo were 12.2 and $12.9 \%$, and the EO accounted for 11.1 and $11.9 \%$ in 2001 and 2019 maps, respectively. Overall accuracies of maps were between 85.5 and $89.1 \%$ with kappa coefficient of 0.83 and 0.87 . According to Landis and Koch (1977), the value of kappa coefficient is categorized into three, a value between 0.40 , representing poor

Page 5/19 
agreement, between 0.40 and 0.80 , representing moderate agreement and above 0.80 representing strong agreement. Therefore, the kappa coefficient results of this study indicated strong agreement for each of the produced maps, and the overall accuracies were in acceptable range to monitor the bamboo forest dynamics over the last 34 years.

\section{Spatio-temporal Bamboo forest cover changes in the study area}

In 1985, bamboo covered 5.1\% (5,277.1 ha) when non-bamboo vegetation types (woodland, shrub/bushland and grassland) comprised 33\% (34,464,7 ha) and non-vegetated land (agricultural land and barren land) covered the largest area (62\%) (Table 5; Fig. 5). The spatial distribution of bamboo was scattered along with grasses, shrubs and forests, where thick bamboo forests were found in the peripheries of north-western, north-eastern and western parts of the District (Fig. 5).

Significant decline in bamboo forest had occurred in 2001 when the bamboo forests suffered the greatest devastation and shirked by 3.5\% (Table 5). Compared with the bamboo, non-bamboo vegetation exhibited a slight reduction by $1.86 \%$. Conversely, non-vegetated land had increased by $5.4 \%$. The 2001 map clearly illustrates that concentrated bamboo forest was hardly found except at few places in the eastern part of the District. It was rather possible to observe scattered bamboo patches, mostly, at the north-eastern and eastern parts of the study District (Fig. 5). Generally, in the first change analysis period (1985 - 2001), the bamboo forests had declined at a rate of $3.5 \%$ (3,602 ha).

The 2019 map (Fig. 5) illustrates a good bamboo forest cover, implying that the bamboo has been rehabilitated from degradation and increased significantly. In this period, dispersed bamboo forests were common in most areas of southern, north-western and north-eastern parts, while some dense bamboo forests were found in the peripheries of north-western, central, eastern and north-eastern portions of the District. The bamboo has own $4.25 \%$ of the District, i.e. covering 4,446.11 ha. However, except the grassland, non-bamboo vegetation and non-vegetated land declined by $1.26 \%$ and $4.36 \%$, respectively.

In the second change analysis period (2001 - 2019), the bamboo forest increased from $1.6 \%(1,675.15 \mathrm{ha})$ to $4.25 \%(4,446.11 \mathrm{ha})$ at a rate of $2.65 \%(2,771$ ha). However, over the study period (1985 - 2019), the bamboo forest declined by $0.8 \%(831.14 \mathrm{ha})$. Generally, results from this study revealed that bamboo has experienced significant spatial and temporal changes over the last three and half decades (1985 - 2001) in the study District.

\section{Drivers of bamboo forest dynamics in the study area}

In the present study area, there are many intertwined and connected factors or drivers for bamboo dynamics. Efforts were made to identify drivers of bamboo dynamics and a total of 13 factors were perceived by respondents as main drivers of bamboo dynamics in the study area (Table 7). However, there were variations about each of the drivers to which the local people viewed as important drivers of bamboo forest dynamics. Agricultural land expansion, wildfire, free grazing, lack of regulatory mechanisms and expansion of settlement areas were perceived as the top five drivers respectively.

Agricultural land expansion was viewed as the most important drivers by $85.6 \%$ of the respondents. According to the FGD participants and KII, bamboo forest degradation was associated with population pressure. According the CSA, the population in Mandura District has escalated. The population of the study area was 18,017 in 1984, 22,593 in 1994, and 40,746 in 2007. Over the last 23 years, the population was doubled. This implies that as the population is growing over time, demand for agricultural land, bamboo products and settlement increases. agricultural land expansion is a key driver for bamboo degradation in the study area. The FDG participants added that people deforest bamboo forests to expand agricultural land as they prefer the immediate benefit and ignore longterm benefit they could get from bamboo forests.

Induced by population pressure, expansion of settlement areas (68.8\%) and increasing demand for bamboo products (63.8\%), were also amongst the main drivers mentioned by respondents in the study area.

Wildfire was the second most important driver mentioned by $76.9 \%$ of respondents in the study area. It was also understood from the account of FGDs participants and field observation protocol that wildfire was one of the major driver for bamboo dynamics. In the study area, very commonly, the community induce fire on natural forests including bamboo grooves to stimulate the growth of grass for their livestock and or to open up the forest for hunting. Hence, the fire burns bamboo culms and the emerging bamboo shoot which could let the clump ceased.

Moreover, Cattle keeping and grazing system was perceived by $76.3 \%$ of the respondents as the third important driver for bamboo dynamics in the study District. The cattle are allowed free to graze on any land use system including bamboo forest. When the cattle go through bamboo stands, they graze the bamboo shoot and leaves which are critical for development of the bamboo plant. Weak regulatory and enforcement was ranked as the fourth driver by $69.4 \%$ of the respondents. Similarly, improper harvesting was mentioned by $63.1 \%$ participants as driver bamboo forest cover change. In this regard, FGD participants justified that there is clear gap on use and management of bamboo forest. They added that most of the bamboo resources of the district are natural or stateowned bamboo forests. However, still now, there is no rule to govern the use of these natural or state-owned bamboo forests, which lead to over exploitation and degradation of bamboo resources.

Conflict $61.9 \%$, mass flowering (52.5\%) and tenure (43.8\%) were viewed as other important drivers of bamboo forest dynamics in the study area. However, fuelwood $(7.06 \%)$ and charcoal production (5.14\%) were perceived by respondents as the least preferred drivers of bamboo dynamics.

As we understood from field observation protocol and participants reflection during FGDs, conflict and insecurity problem has prohibited bamboo cultivators to control the wildfire and keep cattle away from the bamboo stands. Recently, insecurity and conflict are becoming common social problems in the district. Hence, when problem happens, people improperly harvest and loot bamboo culms, bamboo shoot, send their cattle for grazing and sometimes fire the 
bamboo stands. Moreover, they viewed mass flowering as important natural factor for bamboo degradation. They added that bamboo flowers between $30-35$ years, at this time bamboo could regenerate if it is free from animal and human interference though it does not work in the study area.

\section{Discussions}

This study revealed that bamboo had experienced significant spatio-temporal changes over the last three and half decades (1985 - 2019). In the base year (1985), bamboo covered 5.1\% (5,277.1 ha) of the study area. Significant decline in bamboo forest had occurred in 2001 when the bamboo forests suffered the greatest devastation and shirked to $1.6 \%$. In 2019, the bamboo has been rehabilitated from degradation and increased significantly. However, the net change over the study periods was negative where the bamboo forests declined by $0.8 \%$ ( $831.14 \mathrm{ha}$ ). This finding is in agreement with previous studies (Embaye 2000; Lobovikov et al. 2007; Emiru and Taye 2012; Mekonnen et al. 2014; Desalegn and Tadesse 2015; Bessie et al. 2016) which reported that bamboo forests in Ethiopia are declining from time to time.

In the study District, a range of drivers were identified for bamboo forest cover change occurred over the last three and half decades. The local people had perceived responsible drivers of the change though their level is different. These drivers are broadly classified as direct or proximate and indirect or underlying factors. In this study, it was fund that emanated from population pressure, agricultural land expansion, was the most important driver of bamboo forest cover change. In line with this, similar studies conducted so far (Embaye 2000; INBAR 2010; Bessie et al. 2016; Zhao et al. 2018; Boissière et al. 2019) reported that expansion of agricultural land was the man driver for bamboo forest cover change in lowlands of North-western Ethiopia.

Wildfire was identified as the second most important driver of bamboo forest change. In the study district, people induce fire to stimulate the growth of grasses for their livestock and or to open up the forest for hunting. At that time, the fire burns bamboo culms and the emerging bamboo shoots, which could let the clump ceased. Fire has devastating effect if it occurs after flowering of bamboo as it also burns bamboo seeds. According to Mulatu et al. (2016) seedling establishment is unlikely on burnt sites since the fire affects both the soil seedbank and the regenerated seedlings. In this regard, Embaye (1998); Kindu and Mulatu (2009); Sertse et al. (2011); Boissière et al. (2019) also documented that fire is one of the principal factor for bamboo forest cover change in Ethiopia.

Cattle keeping and grazing system was one of the most significant drivers for bamboo forest cover change in the study area. The cattle are allowed to graze freely on any of land uses including bamboo stands. When the cattle go through bamboo stands, they graze bamboo shoots and lives, which are critical for the development of the plant. Thus, free grazing has continued as a main driver for bamboo forest degradation in the study area. This finding is in agreement with the findings of Kindu and Mulatu (2009); Bessie et al. (2016); Durai et al. (2018) that found open grazing system as influential factor for bamboo forest degradation.

Increasing demand for bamboo products and expansion of settlement area driven by population growth were amongst the main drivers for bamboo forest cover change. According to the CSA, the population of the study area was 18,017 in 1984, 22,593 in 1994, and 40,746 in 2007 . Over the last 23 years, the population was doubled. As the population grew over time, demand for bamboo products and settlement plot increased, which subsequently led people to clear bamboo forests for construction material and more space for resident plots. In connection with this, Zhao et al. (2018) noted the natural bamboo forests are under threat from deforestation and degradation for people are clearing them away to have more space for agricultural activities and residential plots.

Conflict and insecurity problem was a major driver that contributed for bamboo forest cover change. It had triggered other drivers like fire and free grazing to cause a change in bamboo forest cover. According to the FGD participants, the prevalence of conflict and insecurity risk had prohibited bamboo cultivators to control fire and keep cattle away from the bamboo stands. Recently, insecurity and conflict are becoming common social problems in the study district. Hence, when problem happens, people improperly harvest and loot bamboo stands, bamboo shoots; send their cattle for grazing and sometimes fire bamboo stands.

Policy related factors like weak forest protection and tenure were among the underlying driving forces for bamboo forest cover change. In the study district, there is no strict rule to govern the use and management of bamboo forests, mainly, the natural bamboo forests. Hence, natural bamboo forests are considered as common pool resources which lead to overexploitation and degradation of bamboo. However, compared to the natural bamboo forests, bamboo grown on private land are protected. In this regard, Durai et al. (2018); Zhao et al. (2018); Boissière et al. (2019), reported that coupled with other anthropogenic factors, the absence of regulation and enforcement mechanisms triggered the degradation of bamboo in north-western Ethiopia.

Improper harvesting was the other cause for bamboo cover change. During flied observation, we found that bamboo management in the study area was improper and unsustainable. There was an instance of harvesting very young bamboo culm while many old bamboo culms lie down on bamboo clumps. During FGDs, participants justified that they have knowledge gap on bamboo resource management. They relied on the knowledge they gained from their fathers and forefathers and personal experiences. In this regard, Embaye (2000); Durai et al. (2018) reported that lack of awareness and dearth of scientific knowledge on its growth, management, harvesting, processing and utilization are major causes for bamboo degradation.

Mass flowering was an important natural phenomena causing bamboo forest cover change in the study landscape. According FGD participants, lowland bamboo flowers between 30 to 35 years. At this time, it has to be kept free from animal and human interference to get regenerated. However, people tend to send their cattle for grazing, and otherwise make a fire on it. For this reason, bamboo regeneration after mass flowering was limited in the study area. This finding is in agreement with Embaye (2000); Sertse et al. (2011); Durai et al. (2018); Dereso (2019) which reported that the recent gregarious flowering and die back of bamboo, and lack of efforts to assist regeneration, coupled with anthropogenic forest fire and free grazing has resulted in poor regeneration and degradation and loss of bamboo forests.

In the study District, fuelwood and charcoal production were the least significant drivers for bamboo dynamics. As we understood from portfolio of FGDs, the local people did not prefer bamboo for fuelwood and charcoal. Although they are being depleted, there are natural forests that have higher biomass 
accumulation to use as sources of charcoal and fuelwood. For this reason, fuelwood and charcoal production are insignificant drivers for bamboo forest cover change in the study area. This finding disagrees with the findings of (Bessie et al. 2016) which reported that firewood and charcoal production are the main drivers for bamboo forest degradation in lowlands of north-western Ethiopia.

\section{Conclusions}

Understanding the bamboo forest cover change has enormous potential to facilitate sustainable management of the resource. This study examined the spatio-temporal bamboo forest cover change in Lower Beles River Basin, North-western Ethiopia for the last 34 years (1985 - 2019). Under data scarce environment, we employed simple, but critical techniques to offset the limitations of the coarse resolution Landsat image, and improve the accuracy of mapping of bamboo. First, we integrated vegetation indices, Normalized Deference Vegetation Index (NDVI) technique with supervised (pixel-based) classification scheme. The NDVI technique, with different threshold values, was employed to extract features. Secondly, image-fusion was applied to merge the high-resolution panchromatic image (band 8) of Landsat 7 and 8 with the multi-spectral images to have an image with better quality. Moreover, as bamboo forests are, often, scattered with other vegetation types, we took a large number of samples from bamboo land cover class to improve the classification accuracy.

According to the resultant maps, bamboo has experienced significant spatio-temporal change over the study period (1985 - 2019$)$ in the study District. The bamboo forests dwindled substantially between 1985 and 2001, specifically during 2001. During this period, the bamboo forests were devastated by $3.4 \%$ and the District lost 3,602 ha of bamboo resource. In 2019, the bamboo has been rehabilitated from degradation and increased significantly. However, the net change over the study periods was negative where the bamboo forests declined by $0.8 \%$ ( 831.14 ha). The observed changes in bamboo forest cover was driven by an interplay of multiple factors. Agricultural land expansion, wildfire, free grazing, lack of regulatory mechanisms and improper harvesting and expansion of settlement areas were the top five drivers respectively while conflict, mass flowering and tenure contributed for the change.

Generally, the bamboo forests deserve great attention, and the results from this study imply the need for the concerted efforts of stakeholders for sustainable management, utilization and conservation of the bamboo resources. Improving bamboo forest protection, community awareness, introduction of controlled grazing system, and incentive and motivation for bamboo growers are among the possible solutions forwarded to conserve and sustain the bamboo resources.

\section{Declarations}

Authors contribution: All authors contributed to the study conception and design. Material preparation, data collection and analysis were performed by Shiferaw Abebe, Amare Sewnet Minale and Demel Teketay. The first draft of the manuscript was written by Shiferaw Abebe and all authors commented on the previous version of the manuscript. All authors read and approved the final manuscript.

Funding: This work was financially supported by the International Foundation for Science (IFS), Stockholm, Sweden (grant number D/6296-1).

Conflict of interest: The authors declare that they have no conflict of interest.

Ethics approval and consent to participate: Not applicable

Consent for publication: Not applicable

Availability of data and material: Not applicable

Acknowledgements: The authors would like to thank the International Foundation for Science (IFS) for providing financial support to the first author. The authors are delighted to express their gratitude to the farmers, experts, and local administrators of Mandura District for their support throughout the field work.

\section{References}

Addisu G (2010) Hydrogeological and Hydrogeochemical Characterisation of Beles River Basin, Northwestern Ethiopia. MSc Thesis, Addis Ababa University Akinlabi ET, Anane-Fenin K, Akwada DR (2017) Bamboo the multipurpose plant. Springer International Publishing, Cham. Springer International Publishing. https://doi.org/10.1007/978-3-319-56808-9

Alemu B, Garedew E, Eshetu Z,\& Kassa H (2014) International Research Journal of Agricultural Science and Soil Science. Int Res J Agric Soil Sci 4:150-158. https://doi.org/10.14303/irjas.2014.055

Azzari G, Lobell DB (2017) Landsat-based classification in the cloud: An opportunity for a paradigm shift in land cover monitoring. Remote Sens Environ 202:64-74. https://doi.org/10.1016/j.rse.2017.05.025

Ben-zhi Z, Mao-yi FU, Jin-zhong XIE, et al (2005) Ecological functions of bamboo forest: Research and Application. J For Res 16:143-147. https://doi.org/1007-662X(2005)02-0143-05

Bessie S, Beyene F, Hundie B, et al (2016) Land Use/Land Cover Change and its Effects on Bamboo Forest in Benishangul Gumuz Region, Ethiopia. Int J Sustain Dev World Policy 5:1-11. https://doi.org/10.18488/journal.26/2016.5.1/26.1.1.11 
Bhandari AK, Kumar A, Singh GK (2012) Feature Extraction using Normalized Difference Vegetation Index (NDVI): A Case Study of Jabalpur City. Procedia Technol 6:612-621. https://doi.org/10.1016/j.protcy.2012.10.074

Boissière M, Beyessa M, Atmadja S (2019) Guiding principles for sustainable bamboo forest management planning: Benishangul-Gumuz Regional State (BGRS). Rome, Italy

Carvalho AL De, Nelson BW, Bianchini MC, et al (2013) Bamboo-Dominated Forests of the Southwest Amazon: Detection, Spatial Extent, Life Cycle Length and Flowering Waves. PLoS One 8:e54852. https://doi.org/10.1371/journal.pone.0054852

Congalton RG (1991) A review of assessing the accuracy of classifications of remotely sensed data. Remote Sens Environ 37:35-46. https://doi.org/10.1016/0034-4257(91)90048-B

Creswell JW (2009) Research Design Qualitative, Quantitative, and Mixed Approaches, Third. SAGE Publications Ltd., Thousand Oaks, California

Central Statistical Agency (CSA) (1984) The 1984 Population and Housing Census of Ethiopia. Addis Ababa, Ethiopia

Central Statistical Agency (CSA) (1994) The 1994 Population and Housing Census of Ethiopia. Addis Ababa, Ethiopia

Central Statistical Agency (CSA) (2007) The 2007 Population and Housing Census of Ethiopia. Addis Ababa, Ethiopia

Dereso Y (2019) Regeneration study of lowland bamboo (Oxytenanthera abyssinica A. R. Munro) in mandura district, Northwest Ethiopia. Biodivers Int J 3:1826. https://doi.org/10.15406/bij.2019.03.00122

Desalegn G, Tadesse W (2015) Resource Communication. Resource potential of bamboo, challenges and future directions towards sustainable management and utilization in Ethiopia. For Syst 23:294-299. https://doi.org/http://dx.doi.org/10.5424/fs/2014232-03012

Du H, Li Y, Zhu D, et al (2018) Mapping Global Bamboo Forest Distribution Using Multisource Remote Sensing Data. IEEE J Sel Top Appl Earth Obs Remote Sens 11:1458-1471. https://doi.org/10.1109/JSTARS.2018.2800127

Durai J, Assefa F, Aseffa S, et al (2018) Value Chain Analysis and Market Assessment of Bamboo Products in Ethiopia. International Bamboo and Rattan Organization, Beijing, China.

Embaye K (2000) The Indigenous Bamboo Forests of Ethiopia: An Overview. AMBIO A J Hum Environ 29:518-521. https://doi.org/10.1579/0044-744729.8.518

Embaye K (1998) The Indigenous Bamboos of Ethiopia: A Call for Attention and Action. Swedish University of Agricultural Science, Uppsala.

Emiru TS, Taye AA (2012) Land use / cover dynamics in lowland Ethiopia since 1957: the case of Mandura district, Benshangul-Gumuz Regional State. J Biodivers Environ Sci 2:36-49

Endalamaw T, Lindner A, Pretzsch J (2013) Indicators and Determinants of Small-Scale Bamboo Commercialization in Ethiopia. Forests 4:710-729. https://doi.org/10.3390/f4030710

Environment, Forest and Climate Change Commission of Ethiopia (EFCCC) (2020) Ethiopian Bamboo Development Strategy and Action Plan (2019 - 2030). Addis Ababa, Ethiopia.

Fan H, Fu X, Zhang Z, Wu Q (2015) Phenology-Based Vegetation Index Differencing for Mapping of Rubber Plantations Using Landsat OLI Data. Remote Sens 7:6041-6058. https://doi.org/10.3390/rs70506041

Fava F, Colombo R (2017) Remote sensing-based assessment of the 2005-2011 bamboo reproductive event in the arakan mountain range and its relation with wildfires. Remote Sens 9:. https://doi.org/10.3390/rs9010085

Food and Agriculture Organizations of the United Nations (FAO) (2016) Map Accuracy Assessment and Area Estimation Map Accuracy Assessment and Area Estimation: A Practical Guide. Rome, Italy

Gandhi GM, Parthiban S, Thummalu N, Christy A (2015) Ndvi: Vegetation Change Detection Using Remote Sensing and GIS - A Case Study of Vellore District. Procedia Comput Sci 57:1199-1210. https://doi.org/10.1016/j.procs.2015.07.415

GIZ-LUSO Consult Gmbh (1997) Bamboo Management in Ethiopia.

Goswami J, Tajo L, Sarma KK (2010) Bamboo resources mapping using satellite technology. Curr Sci 99:650-653

Han N, Du H, Zhou G, et al (2014) Object-based classification using SPOT-5 imagery for Moso bamboo forest mapping. Int J Remote Sens 35:1126-1142. https://doi.org/10.1080/01431161.2013.875634

Huy B, Long TT (2019) A Manual for Bamboo Forest Biomass and Carbon Assessment. International Bamboo and Rattan Organization. Beijing, China 
Kelbessa E, Bekele T, Gebrehiwot A, Hadera G (2000) A Socio-economic Case Study of the Bamboo Sector in Ethiopia: An analysis of the Production-toConsumption system. Addis Ababa, Ethiopia

Kindu M, Mulatu Y (2009) Status of bamboo resource development, utilization, and research in Ethiopia: A review. Ethiop J Nat Resour 1:79-98

Kindu M, Schneider T, Teketay D, Knoke T (2015) Drivers of land use/land cover changes in Munessa-Shashemene landscape of the south-central highlands of Ethiopia. Environ Monit Assess 187:452. https://doi.org/10.1007/s10661-015-4671-7

Kindu M, Schneider T, Teketay D, Knoke T (2013) Land Use/Land Cover Change Analysis Using Object-Based Classification Approach in MunessaShashemene Landscape of the Ethiopian Highlands. Remote Sens 5:2411-2435. https://doi.org/10.3390/rs5052411

Landis JR, Koch GG (1977) The Principles and Practice of Management. Biometrics 33:159-174. https://doi.org/10.2307/2519310

Li M, Li C, Jiang H, et al (2016) Tracking bamboo dynamics in Zhejiang, China, using time-series of Landsat data from 1990 to 2014 . Int J Remote Sens 37:1714-1729. https://doi.org/10.1080/01431161.2016.1165885

Li X, Du H, Mao F, et al (2020) Mapping spatiotemporal decisions for sustainable productivity of bamboo forest land. L Degrad Dev 31:939-958. https://doi.org/10.1002/ldr.3509

Ling M, Christensen M, Donnison A, et al (2016) Scoping study to inform the Global Assessment of Bamboo and Rattan (GABAR). United Natios Development Program. United Kingdom

Liu C, Xiong T, Gong P, Qi S (2018) Improving large-scale moso bamboo mapping based on dense Landsat time series and auxiliary data: a case study in Fujian Province, China. Remote Sens Lett 9:1-10. https://doi.org/10.1080/2150704X.2017.1378454

Liu JG, Mason PJ (2016) Image processing and GIS for remote Sensing: Techniques and applications, Second Edi. John Wiley \& Sons, Ltd., The atrium, Southern Gate, Chichester, West Sussex, P019 8SQ, UK Editorial.

Lobovikov M, Paudel S, Marco P, et al (2007) World bamboo bamboo resources: a thematic study prepared in the framework of the Global Forest Resource Assessment 2005. International Bamboo and Rattan Organization, Beijing, China. Rome, Italy

Lossou E, Owusu-Prempeh N, Agyemang G (2019) Monitoring Land Cover changes in the tropical high forests using multi-temporal remote sensing and spatial analysis techniques. Remote Sens Appl Soc Environ 16:100264. https://doi.org/10.1016/j.rsase.2019.100264

Lune H, Berg BL (2017) Methods for the Social Sciences Global Edition, Nineth. Pearson Education Limited, England

Mekonnen Z, Worku A, Yohannes T, et al (2014) Bamboo Resources in Ethiopia: Their value chain and contribution to livelihoods. Ethnobot Res Appl 12:511524

Mulatu Y, Alemayehu A, Tadesse Z (2016) Biology and Management of Indigenous Bamboo Species of Ethiopia. Addis Ababa, Ethiopia

Nath AJ, Lal R, Das AK (2015) Managing woody bamboos for carbon farming and carbon trading. Glob Ecol Conserv 3:654-663.

https://doi.org/10.1016/j.gecco.2015.03.002

International Bamboo and Rattan Network (INBAR) (2010) Study on Utilization of Lowland Bamboo in Benishangul Gumuz Region, Ethiopia. 1-55. International Bamboo and Rattan Organization, Beijing, China.

Nyssen J, Fetene F, Dessie M, et al (2018) Persistence and changes in the peripheral Beles basin of Ethiopia. Reg Environ Chang 18:2089-2104. https://doi.org/10.1007/s10113-018-1346-2

Rogan J, Chen D (2004) Remote sensing technology for mapping and monitoring land-cover and land-use change. Prog Plann 61:301-325. https://doi.org/10.1016/S0305-9006(03)00066-7

Sertse D, Disasa T, Bekele K, et al (2011) Mass flowering and death of bamboo: a potential threat to biodiversity and livelihoods in Ethiopia. J Biodivers Environ Sci 1:16-25

Shah S, Sharma D (2015) Land use change detection in Solan Forest Division, Himachal Pradesh, India. For Ecosyst 2:26. https://doi.org/10.1186/s40663015-0050-7

Simonetti E, Simonetti D (2014) Phenology- based land cover classification using Landsat 8 time series. Luxembourg

Sohel MSI, Alamgir M, Akhter S, Rahman M (2015) Carbon storage in a bamboo (Bambusa vulgaris) plantation in the degraded tropical forests: Implications for policy development. Land use policy 49:142-151. https://doi.org/10.1016/j.landusepol.2015.07.011

Sohl TL, Gallant AL, Loveland TR (2004) The Characteristics and Interpretability of Land Surface Change and Implications for Project Design. Photogramm Eng Remote Sens 70:439-448

Thomas M. Lillesand, Ralph W., Kiefer JWC (2007) Remote Sensing and Image Interpretation, 6th edn. Jhon Willey \& Sons.Inc 
Thomas M. Lillesand TML, Kiefer RW, Chipman JW (2015) Remote Sensing and Image Interpretation, Seventh. John Wiley \& Sons, Inc., Hoboken, United States of Ameria

UniversityTsinghua, INBAR (2018) Remote Sensing-Based Regionl Bamboo Resource Assessment Report of Ethiopia, Kenya and Uganda. Beijing, Chaina Wang T, Skidmore AK, Toxopeus AG, Liu X (2009) Understory Bamboo Discrimination Using a Winter Image. Photogramm Eng Remote Sens 75:37-47. https://doi.org/10.14358/PERS.75.1.37

Xu X, Zhou G, Du H, Partida a (2012) Bamboo forest change and its effect on biomass carbon stocks: a case study of Anji County, Zhejiang Province, China. J Trop For Sci 24:426-435

Yilma AD, Awulachew SB (2009) Characterization and Atlas of the Blue Nile Basin and its Sub basins

Yiping L, Yanxia L, Buckingham K, et al (2010) Bamboo and Climate Change Mitigation Bamboo and Climate Change Mitigation: a comparative analysis of carbon sequestration. International Bamboo and Rattan Organization. Beijing, China

Zhang H, Zhuang S, Sun B, et al (2014) Estimation of biomass and carbon storage of moso bamboo (Phyllostachys pubescens Mazel ex Houz.) in southern China using a diameter-age bivariate distribution model. For An Int J For Res 87:674-682. https://doi.org/10.1093/forestry/cpu028

Zhang M, Gong P, Qi S, et al (2019) Mapping bamboo with regional phenological characteristics derived from dense Landsat time series using Google Earth Engine. Int J Remote Sens 40:9541-9555. https://doi.org/10.1080/01431161.2019.1633702

Zhao Y, Feng D, Jayaraman D, et al (2018) Bamboo mapping of Ethiopia, Kenya and Uganda for the year 2016 using multi-temporal Landsat imagery. Int $J$ Appl Earth Obs Geoinf 66:116-125. https://doi.org/10.1016/j.jag.2017.11.008

Zhou G, Meng C, Jiang P, Xu Q (2011) Review of Carbon Fixation in Bamboo Forests in China. Bot Rev 77:262-270. https://doi.org/10.1007/s12229-011-9082z

Zhuang S, Ji H, Zhang H, Sun BO (2015) Carbon storage estimation of Moso bamboo ( Phyllostachys pubescens ) forest stands in Fujian , China. Int Soc Trop Ecol www.tropecol.com 56:383-391

\section{Tables}

Table 1. Characteristics of satellite imageries used in the study.

\begin{tabular}{|llllll|}
\hline Data type & Sensor & Path & Row & Date of acquisition & Resolution \\
\hline Landsat 5 & TM & 170 & 52 & $20 / 04 / 1985$ & $30 \mathrm{~m}$ \\
\hline Landsat 7 & ETM+ & 170 & 52 & $10 / 04 / 2001$ & $30 \mathrm{~m}$ \\
\hline Landsat 8 & OLI_TIRS & 170 & 52 & $19 / 03 / 2019$ & $30 \mathrm{~m}$ \\
\hline
\end{tabular}

Table 2. Definition of thematic land cover classes.

\begin{tabular}{|c|c|}
\hline $\begin{array}{l}\text { Land Cover } \\
\text { Class }\end{array}$ & Description \\
\hline Bamboo & $\begin{array}{l}\text { Land predominantly covered with bamboo forests. It includes bamboo patches that are waiting for restoration or restocking. In some cases, } \\
\text { bamboos are mixed with grasses when they are in the first stages of restoration. }\end{array}$ \\
\hline $\begin{array}{l}\text { Shrub/ } \\
\text { Bush land }\end{array}$ & $\begin{array}{l}\text { It is a land cover less dense than woodland and covered by small trees, bushes, and shrubs two up to five meters tall and a canopy cover of } \\
\text { more than } 20 \% \text {. In some cases, such land covers are mixed with grasses. }\end{array}$ \\
\hline Woodland & Land covered by an open stand of trees taller than five up to $20 \mathrm{~m}$ with a canopy coverage of more than $20 \%$. \\
\hline Grassland & $\begin{array}{l}\text { Small grasses are the predominant natural vegetation. It also includes land with scattered or patches of trees and a land cover used for } \\
\text { grazing and browsing. }\end{array}$ \\
\hline Barren land & $\begin{array}{l}\text { Area that has little or no vegetation cover, which is, mainly, covered by bare soil, rock out crops and land covered by structures, including } \\
\text { roads, towns and rural villages. }\end{array}$ \\
\hline $\begin{array}{l}\text { Agricultural } \\
\text { land }\end{array}$ & Contiguous areas allotted to extended rain-fed crop production, and where, mostly, oil seed, cereals and pulses are managed. \\
\hline
\end{tabular}

Source: Adapted from Emiru and Taye (2012), Alemu et al. (2015) and Bessie et al. (2016)

Table 3. Accuracy assessment results of 1985, 2001 and 2019 image classifications. 


\begin{tabular}{|llllllllllllll|}
\hline & 1985 & \multicolumn{1}{c}{2001} & \multicolumn{7}{c|}{2019} \\
\cline { 2 - 12 } & UA & PA & EC & EO & UA & PA & EC & OE & UA & PA & EC & EO \\
Bamboo cover class & 81.9 & 82.9 & 17.1 & 15.0 & 85.5 & 86.6 & 12.2 & 11.1 & 87.1 & 88.1 & 12.9 & 11.9 \\
\hline Shrub/ Bush land & 83.8 & 82.7 & 13.9 & 17.3 & 87.0 & 84.5 & 11.8 & 14.3 & 87.3 & 84.9 & 12.7 & 15.1 \\
\hline Woodland & 87.0 & 92.3 & 13.0 & 7.7 & 89.4 & 95.4 & 10.4 & 9.1 & 88.2 & 95.2 & 7.4 & 5.0 \\
Grassland & 85.1 & 80.3 & 17.4 & 21.9 & 84.1 & 82.8 & 14.5 & 15.9 & 87.7 & 86.5 & 12.3 & 13.5 \\
\hline Barren land & 88.9 & 87.3 & 11.1 & 14.6 & 90.9 & 90.9 & 9.1 & 9.1 & 93.0 & 91.4 & 7.0 & 8.6 \\
\hline Agricultural land & 86.7 & 89.7 & 13.3 & 10.3 & 93.3 & 91.8 & 8.2 & 6.7 & 92.5 & 93.9 & 7.5 & 6.1 \\
\hline Overall accuracy & 85.5 & 85.5 & 85.5 & 85.5 & 87.9 & 87.9 & 87.9 & 87.9 & 89.1 & 89.1 & 89.1 & 89.1 \\
\hline Kappa statistics & 0.83 & 0.83 & 0.83 & 0.83 & 0.86 & 0.86 & 0.86 & 0.86 & 0.87 & 0.87 & 0.87 & 0.87 \\
\hline
\end{tabular}

Note: UA = User's accuracy; PA = Producer's accuracy; EC = Error of commission; and EO is Error of omission.

Table 4. Confusion matrix of 1985, 2001 and 2019 image classifications.

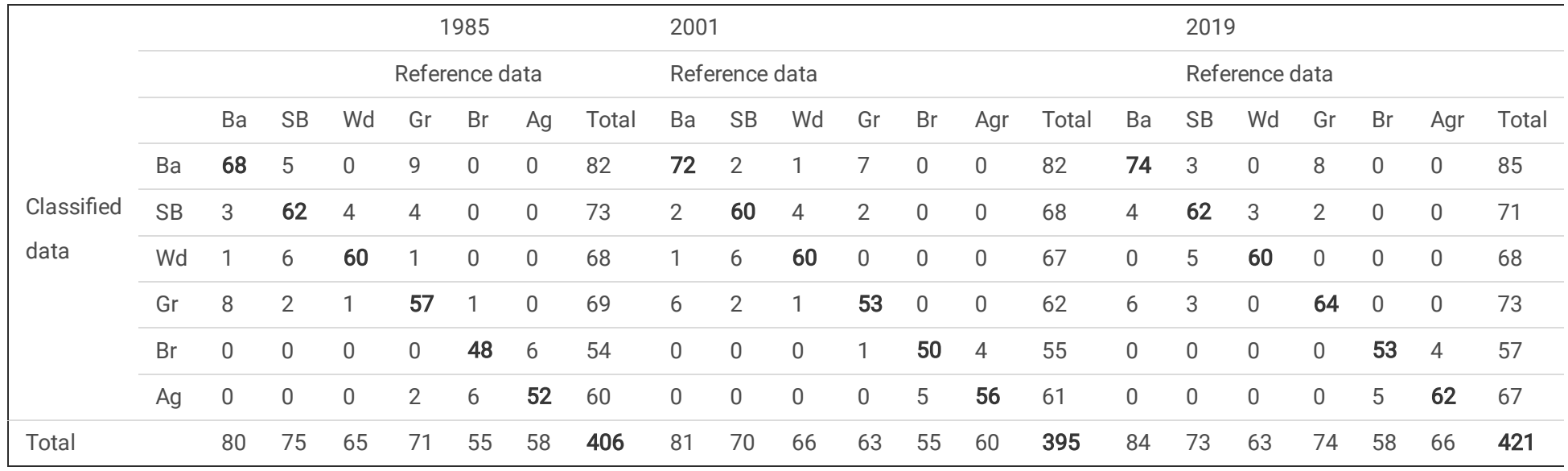

Note: $\mathrm{Ba}=\mathrm{Bamboo} ; \mathrm{SB}=\mathrm{Shrub} / \mathrm{Bush}$ land$; \mathrm{Wd}=$ Woodland; $\mathrm{Gr}=$ Grassland; $\mathrm{Br}=$ Barren land; and $\mathrm{Ag}$ is Agricultural land .

Table 5. Patterns of Land cover changes in 1985, 2001 and 2019 in the study area

\begin{tabular}{|lllllllllllll|}
\hline & 1985 & & 2001 & & 2019 & & $1985-2001$ & & $2001-2019$ & $1985-2019$ \\
\hline Land cover class & $\%$ & Area/ ha & $\%$ & Area/ ha & $\%$ & Area/ ha & $\%$ & Area/ ha & $\%$ & Area/ ha & $\%$ & Area/ ha \\
\hline Bamboo & 5.05 & 5277.25 & 1.60 & 1675.15 & 4.25 & 4446.11 & -3.45 & -3602.10 & 2.65 & 2770.96 & -0.80 & -831.14 \\
\hline Shrub/ Bush land & 14.56 & 15214.78 & 12.52 & 13079.10 & 11.71 & 12242.06 & -2.04 & -2135.68 & -0.80 & -837.04 & -2.84 & -2972.72 \\
\hline Woodland & 7.39 & 7717.34 & 5.01 & 5231.46 & 4.54 & 4748.63 & -2.38 & -2485.88 & -0.46 & -482.83 & -2.84 & -2968.71 \\
Grassland & 11.04 & 11532.57 & 13.53 & 14137.84 & 16.50 & 17237.62 & 2.49 & 2605.27 & 2.97 & 3099.78 & 5.46 & 5705.05 \\
\hline Barren land & 7.26 & 7590.90 & 7.35 & 7676.44 & 8.30 & 8671.01 & 0.08 & 85.54 & 0.95 & 994.57 & 1.03 & 1080.11 \\
\hline Agricultural land & 54.71 & 57167.16 & 60.00 & 62700.00 & 54.69 & 57154.56 & 5.29 & 5532.84 & -5.31 & -5545.44 & -0.01 & -12.60 \\
\hline
\end{tabular}

Table 6. Sample respondents' socio-economic characteristics in the study area.

\begin{tabular}{|ll|}
\hline Household attributes & Value \\
\hline Gender (Male \%) & 78.1 \\
\hline Average household age (years) & 46 \\
\hline Education (literate \%) & 28.1 \\
\hline Means of livelihood (mixed farming \%) & 70 \\
\hline Mean family size (number) & 6 \\
\hline Mean land holding size (ha) & 2.5 \\
\hline
\end{tabular}

Table 7. Drivers of bamboo dynamics perceived by local people in Mandura district. 


\begin{tabular}{|lllll|}
\hline \multirow{2}{*}{ Drivers of bamboo forest dynamics } & Responses & \multicolumn{2}{c|}{ Percent of Cases } \\
\cline { 2 - 4 } & Frequency & Percent & & Rank \\
\hline Agricultural land expansion & 137 & $11.5 \%$ & $85.6 \%$ & 1 \\
\hline Wildfire & 123 & $10.4 \%$ & $76.9 \%$ & 2 \\
\hline Free grazing & 122 & $10.3 \%$ & $76.3 \%$ & 3 \\
\hline Lack of regulatory mechanism & 111 & $9.4 \%$ & $69.4 \%$ & 4 \\
\hline Expansion of settlement area & 110 & $9.3 \%$ & $68.8 \%$ & 5 \\
\hline Increasing demand for bamboo & 102 & $8.6 \%$ & $63.8 \%$ & 6 \\
\hline Improper bamboo harvesting & 101 & $8.5 \%$ & $63.1 \%$ & 7 \\
\hline Conflict and civil war & 99 & $8.3 \%$ & $61.9 \%$ & 8 \\
\hline Mass flowering & 84 & $7.1 \%$ & $52.5 \%$ & 9 \\
\hline Tenure & 70 & $5.9 \%$ & $43.8 \%$ & 10 \\
\hline Infrastructures (road, electricity \& water) & 51 & $4.3 \%$ & $31.9 \%$ & 11 \\
\hline Charcoal & 40 & $3.4 \%$ & $25.0 \%$ & 12 \\
\hline Fuelwood & 37 & $3.1 \%$ & $23.1 \%$ & 13 \\
\hline
\end{tabular}

a. Dichotomy group tabulated at value 1 .

\section{Figures}

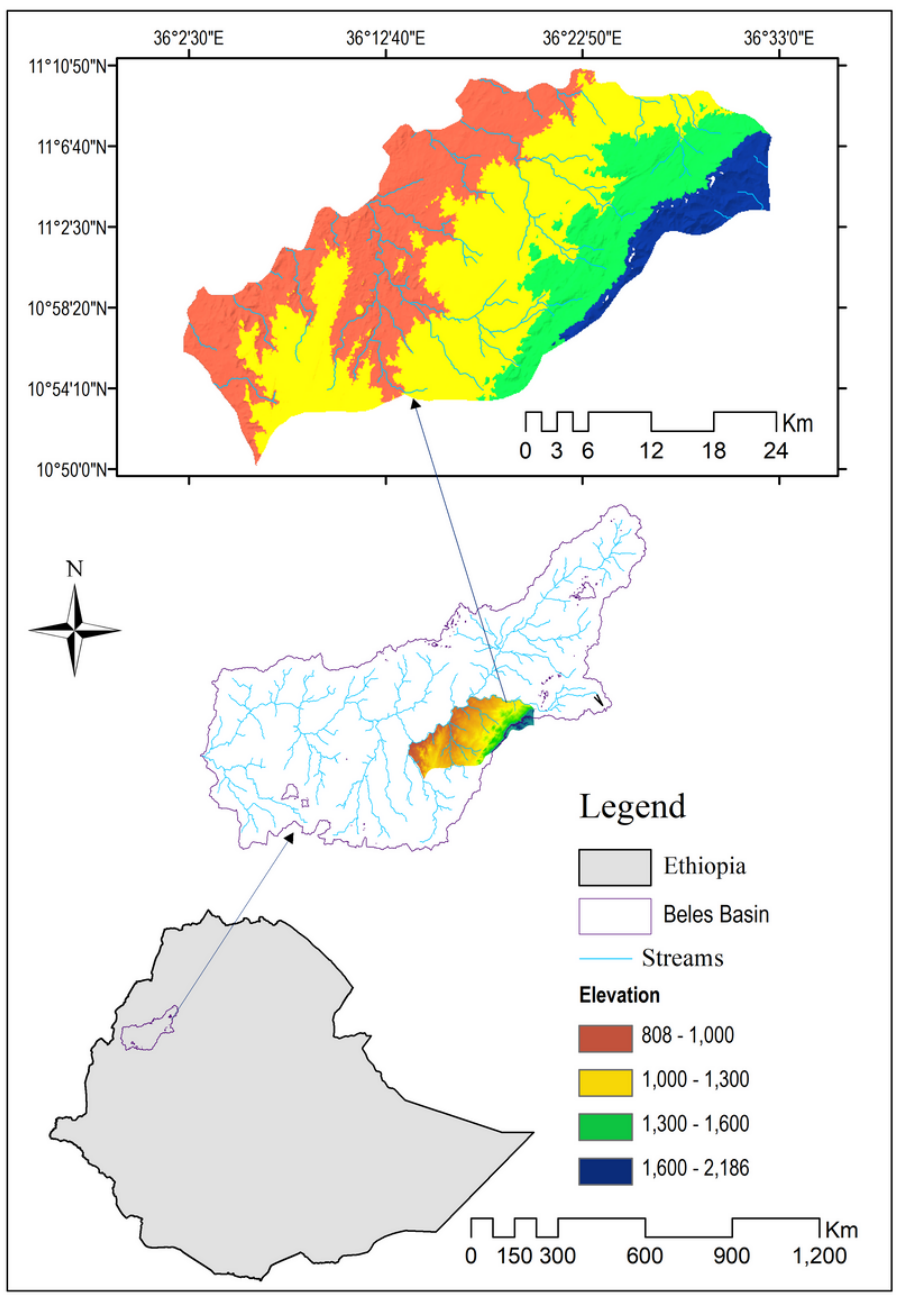

Figure 1 
Map of the study area

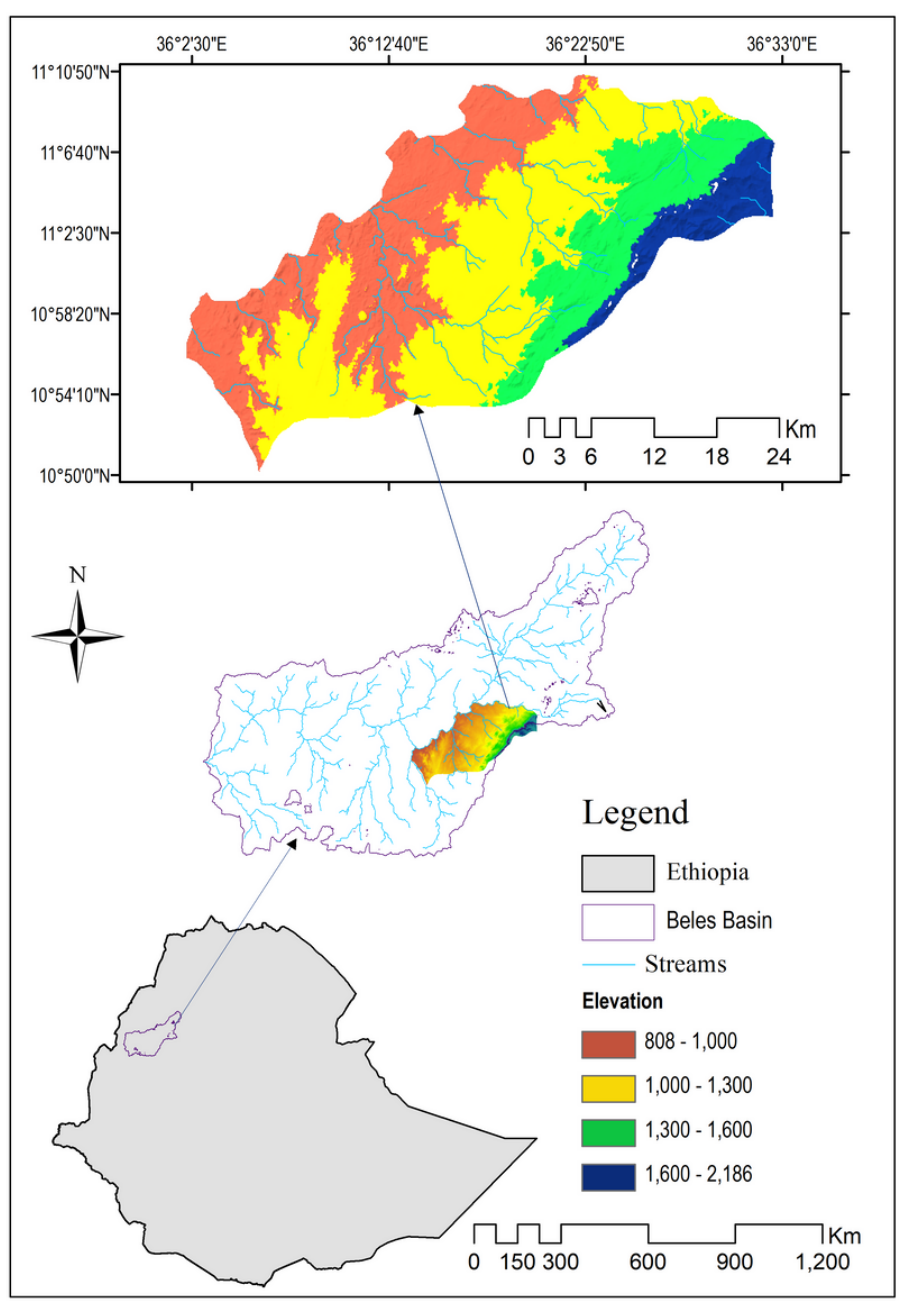

Figure 1

Map of the study area 


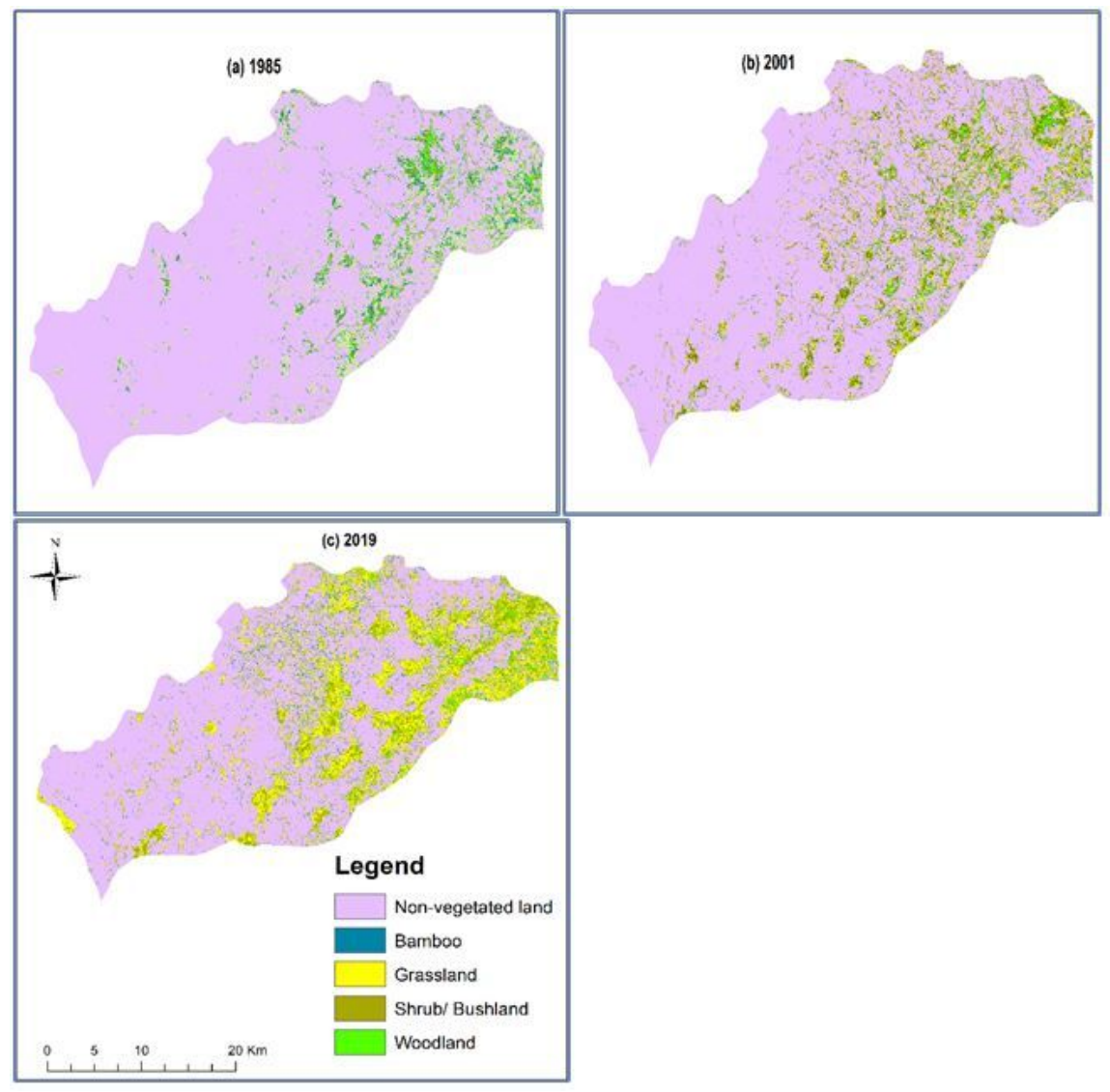

Figure 2

NDVI Map of the study area (1985, 2001 and 2019)

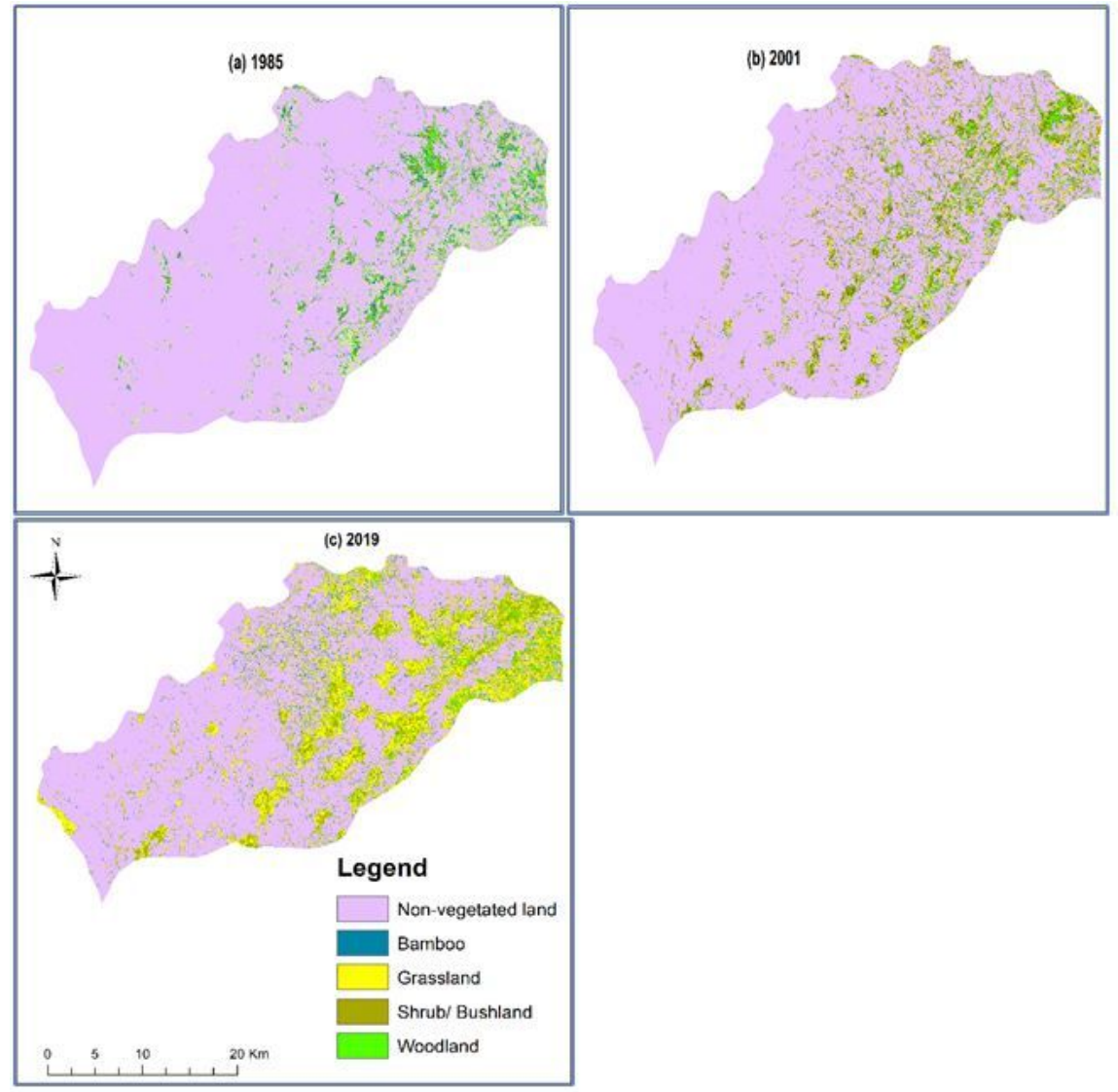

Figure 2

Page 15/19 
NDVI Map of the study area (1985, 2001 and 2019)
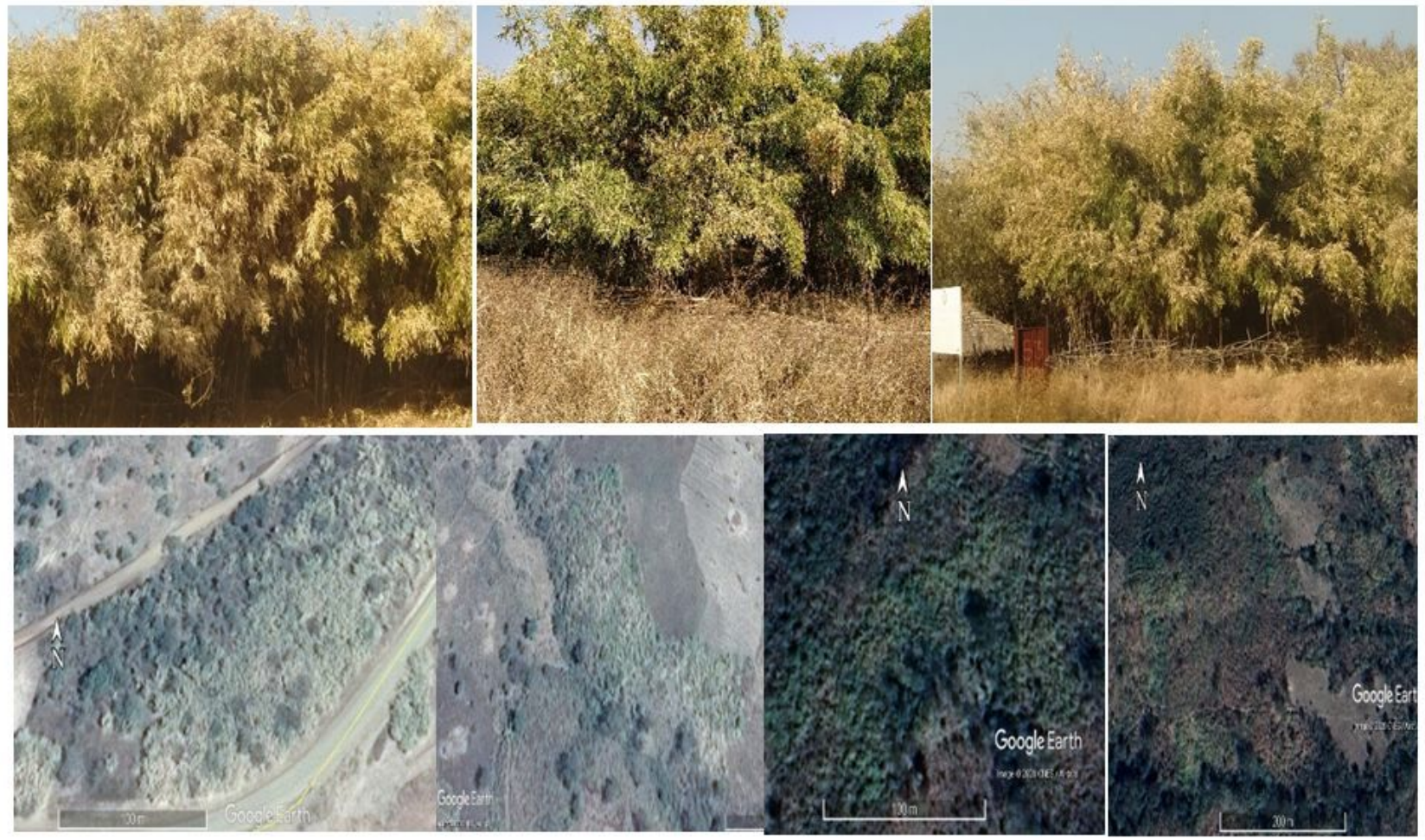

\section{Figure 3}

Photos showing bamboo forests: Field photos ( $a, b$ and $c$ ) taken on bamboo forest; and Photos taken ( $d, e, f$ and $g$ ) from high resolution Google Earth images.
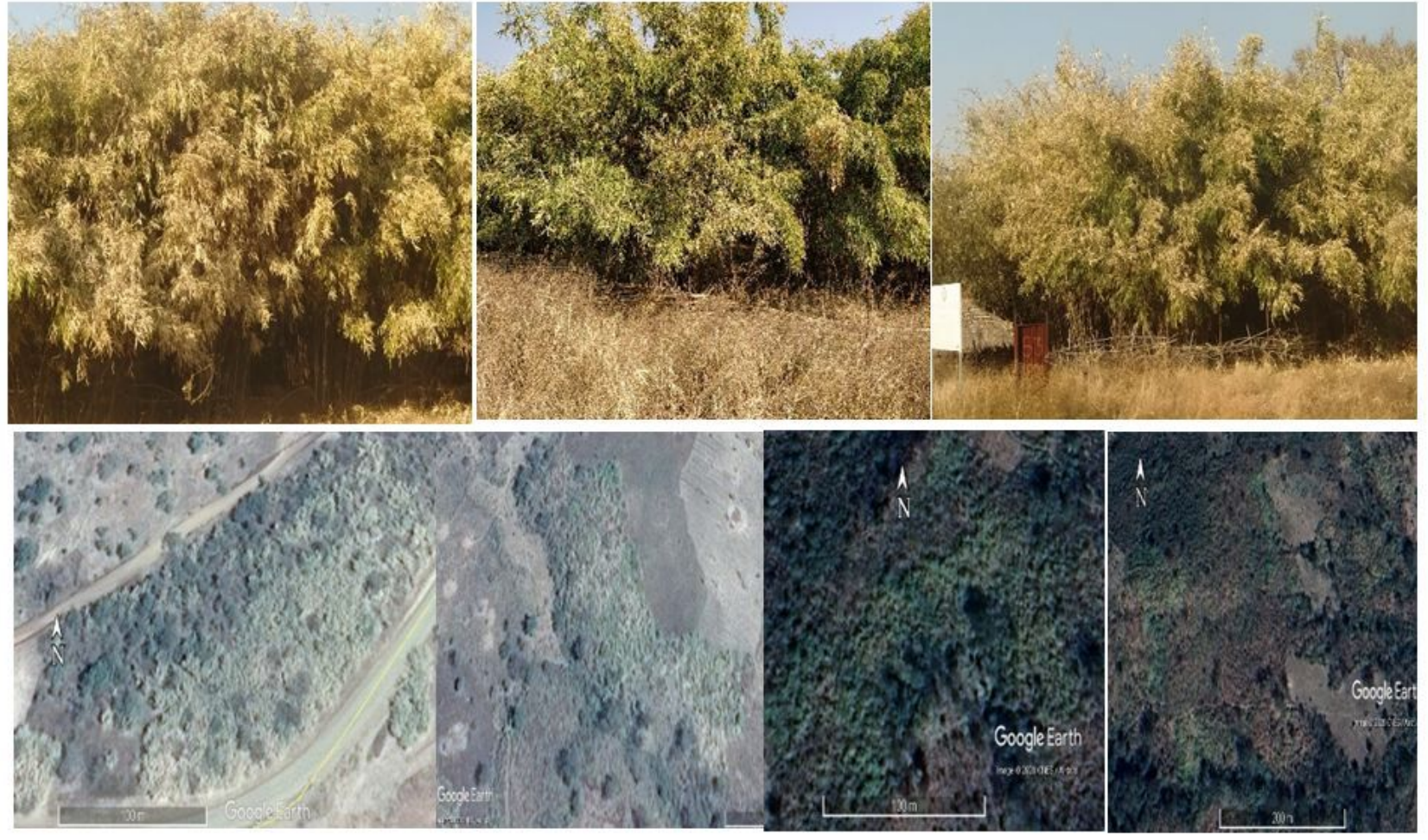

\section{Figure 3}

Photos showing bamboo forests: Field photos ( $a, b$ and $c)$ taken on bamboo forest; and Photos taken ( $d, e, f$ and $g$ ) from high resolution Google Earth images. 


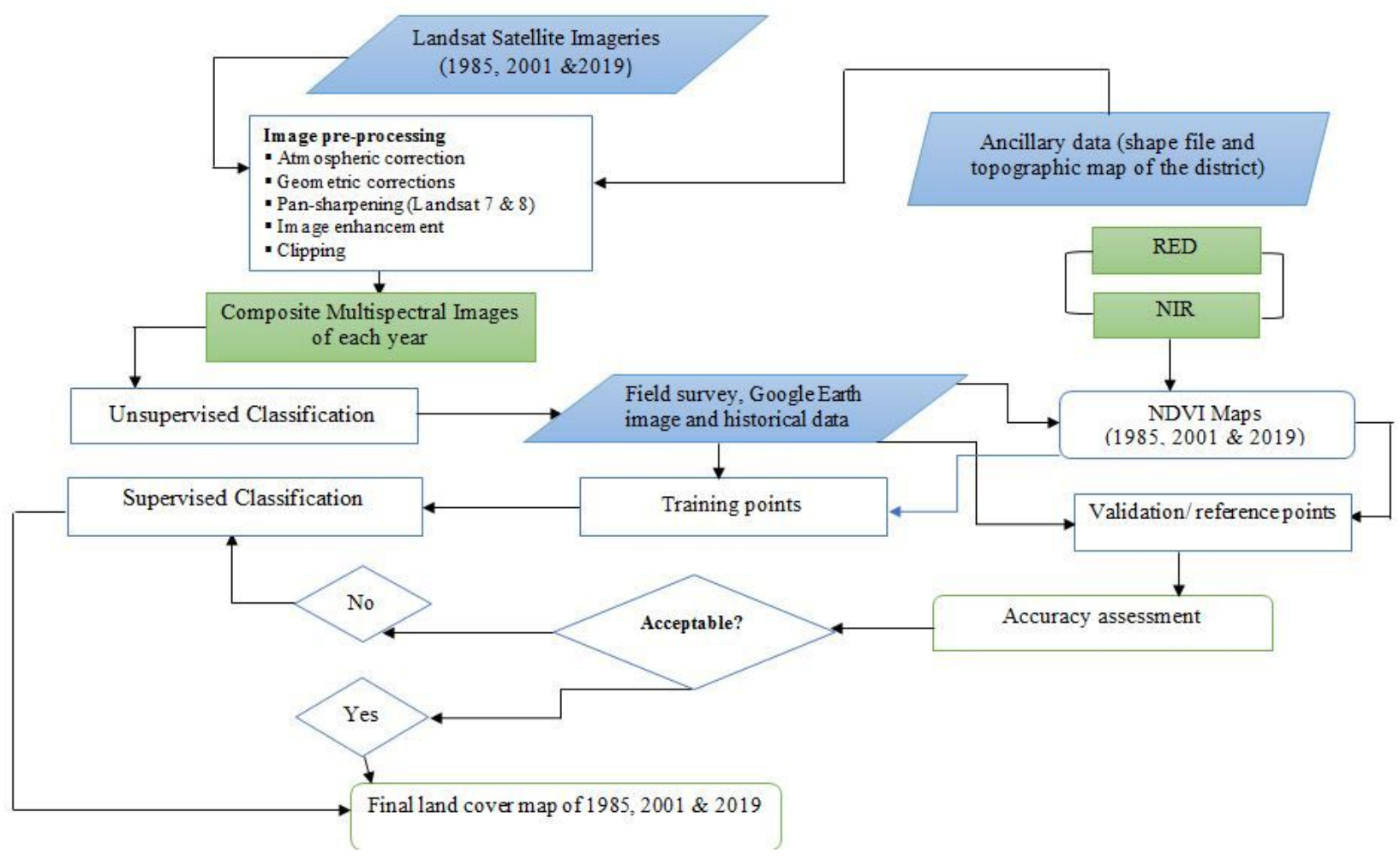

Figure 4

Flowchart showing the procedures employed to prepare the final LULC map

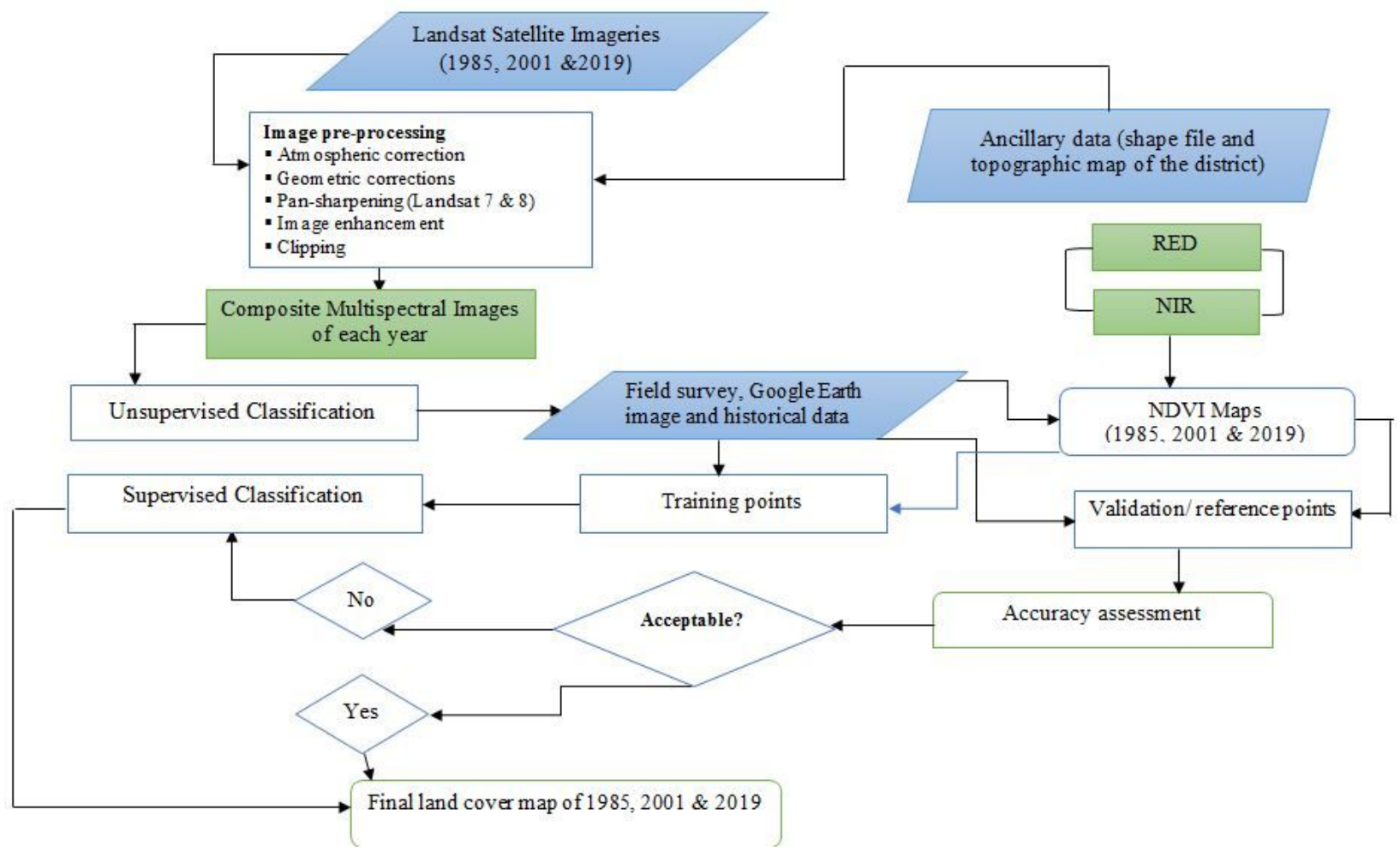

Figure 4

Flowchart showing the procedures employed to prepare the final LULC map 


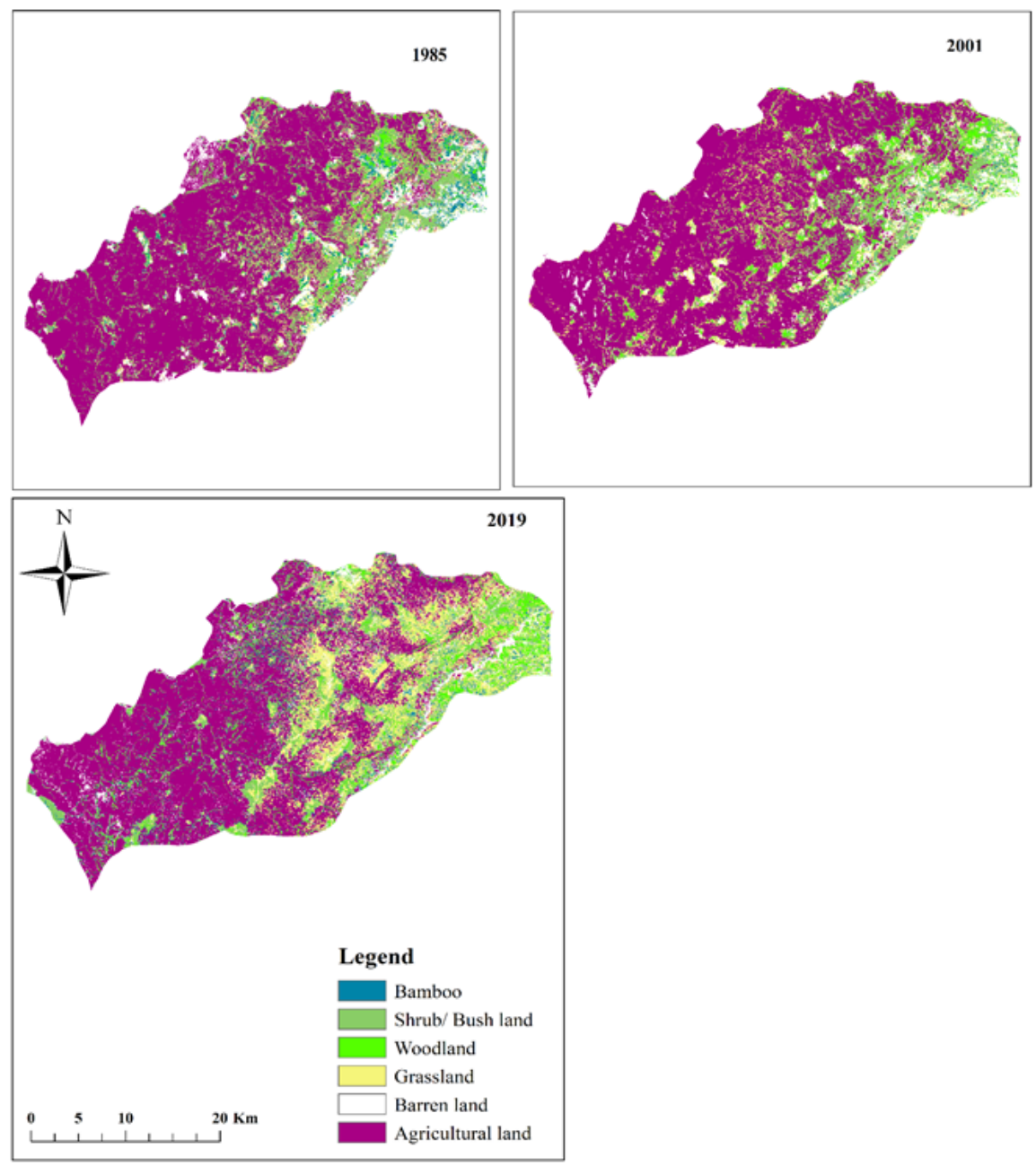

Figure 5

Land cover map of the study area (1985, 2001 and 2019) 


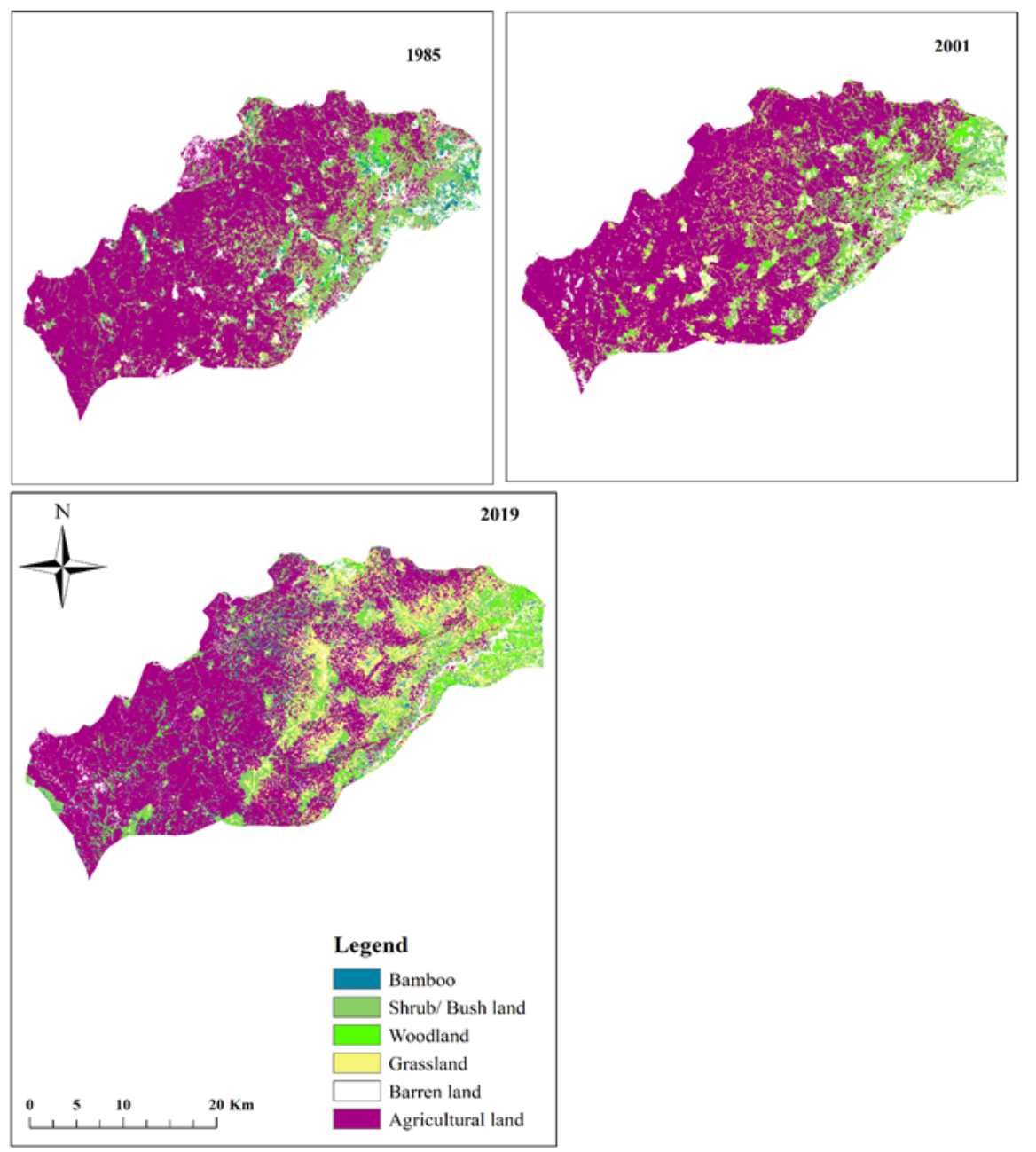

Figure 5

Land cover map of the study area (1985, 2001 and 2019) 